\title{
REMUNERAÇÃO ESTRATÉGICA COMO FORMA DE RESPONSABILIDADE SOCIAL INTERNA - UM ESTUDO DE CASO EM UM COMÉRCIO DE TELECOMUNICAÇÕES EM TANGARÁ DA SERRA - MT
}

\author{
Cássio Jardini Brandão ${ }^{1}$ \\ Luciênio Rosa e Silva Junior ${ }^{2}$
}

\section{RESUMO}

Com o estudo buscou-se analisar o atual Sistema de Remuneração em uma empresa de telecomunicações. Para que o estudo atingisse tal objetivo foram utilizados procedimentos metodológicos dentre os quais citam-se revisão bibliográfica sobre o tema. A fim de buscar dados práticos foi aplicado questionário para saber a percepção dos colaboradores e gestores da organização sobre o sistema de remuneração adotado, além disso, foram analisadas documentações cedidas pela empresa. Tendo em vista o tema da pesquisa foram abordados os variados tipos de Remuneração Estratégica com o intuito de demonstrar as alternativas de recompensas presentes nas organizações. No decorrer do trabalho são citadas as estratégias de remuneração como uma prática de Responsabilidade Social Interna visando mostrar essa estratégia como um fator que visa à melhoria do desempenho, qualidade de vida, motivação e principalmente atendendo as necessidades dos colaboradores envolvidos. Diante de um mercado altamente competitivo é ligeiramente necessário que as empresas utilizem formas variadas de remunerar seus profissionais. Por meio do estudo foi possível verificar na organização alguns pontos falhos na remuneração aplicada. Julgou-se necessário que a empresa adote algumas melhorias na sua política de remuneração, fazendo que esses dados sejam importantes para as próximas tomadas de decisões do négocio.

Palavras Chave: Colaborador, Estratégia, Desempenho

\section{INTRODUÇÃO}

Os novos desafios e as transformações no mundo dos negócios, a competitividade, o ambiente econômico e social das empresas sofre várias alterações em conseqüência da rápida evolução organizacional. Com tantas mudanças, as organizações devem estar preparadas para mudar constantemente e serem mais flexíveis, e para isso as empresas devem buscar novos modelos de negócios, de organização e de gestão.

O comércio é um modelo de organização que tem por objetivo a troca voluntária de produtos e com isso abre concorrência entre empresas para vender suas idéias e conseguir um destaque no mercado. De acordo com o Instituto Brasileiro de Geografia e Estatística (IBGE) o comércio no Brasil teve uma taxa de crescimento significativa no ano de 2010 em relação ao período anterior, revelando que as empresas atualmente procuram investir mais na sua área de negócio e com isso utilizam de métodos e planejamentos para alcançar seus objetivos.

\footnotetext{
${ }^{1}$ Contador formado pela UNEMAT - Campus de Tangará da Serra, kassyo_brandao@ hotmail.com

${ }^{2}$ Mestre em Ciências Ambientais (UNEMAT), Professor do Departamento de Ciências da UNEMAT - Campus de Tangará da Serra, lucieniojunior@unemat.br
} 
Dessa forma, o sistema de remuneração dentro desse processo assumiu um comportamento estratégico, sendo capaz de interferir diretamente na gestão empresarial. Nesse quadro de constantes mudanças não há mais espaço para organizações burocráticas e tradicionais. $\mathrm{Na}$ atualidade os indivíduos procuram empresas inovadoras que vão proporcionar crescimento profissional e qualidade no ambiente de trabalho.

Essas mudanças estão sendo cada vez mais discutidas entre os autores, como por exemplo Chiavenato (2005) e Wood Jr. (2004), que tem o foco voltado em difundir a remuneração como um fator decisivo na competição entre empresas e além disso, revelar que as formas estratégicas de remunerar aumenta o comprometimento dos funcionários e cria um aumento do desempenho individual. Quando se fala em remunerar nas empresas, não se pode pensar em pagar simplesmente um salário para um cargo, a organização deve levar em consideração a remuneração de uma forma que venha beneficiar a empresa e o colaborador. Desse modo, partindo da idéia de analisar os objetivos, necessidades e prioridades da organização e dos profissionais. Quando uma empresa contrata um funcionário existe uma cobrança sobre seu desempenho, como: habilidade, competência, capacidade entre outros que envolve todo um processo de responsabilidade por parte do profissional, sendo assim, o empresário deve desenvolver uma planejamento para atividade da sua empresa que é realizada pelos seus colaboradores, adotando sistemas de planejamento empresarial que relacione a sua equipe de trabalho.

Analisando as dificuldades que as organizações atualmente têm em criar um ambiente organizacional mais propício, elevar o nível de produtividade e motivar suas equipes de trabalho, foi escolhida uma empresa onde se verificou remunerações diferenciadas, sendo entendidas como estratégia organizacional. A empresa objeto do estudo foi classificada atualmente entre as: "150 melhores empresas para se trabalhar no Brasil" no guia da Exame/Você S.A..

Tendo em vista o exposto, essa pesquisa foi realizada com o intuito de relatar a importância de remunerar os seus colaboradores estrategicamente, a capacidade de uma empresa de responder aos desafios está diretamente ligada à formação e as habilidades de seus profissionais. O comércio quando é a atividade fim da organização necessita de profissionais qualificados, os colaboradores da empresa devem estar de comum acordo com o desenvolvimento operacional. Para a instituição e comunidade acadêmica, possibilita maior conhecimento dos tipos de remuneração que pode ser adotada dentro de uma organização, trazendo informações descritivas, bem como as formas estratégicas que podem ser utilizadas. Este trabalho também justifica-se pelo fato de abordar o tema de Responsabilidade Social 
Interna, até então, pouco explorado pela comunidade acadêmica.

Considerando que as empresas na atualidade procuram métodos eficazes para obter melhor desempenho operacional, vender mais seus produtos e ao mesmo tempo ter seus colaboradores motivados, levantou-se a seguinte problemática: Como a Remuneração Estratégica é percebida pelos colaboradores e gestores do comércio de telecomunicações? As hipóteses levantadas foram: 1) A Remuneração Estratégica atende as necessidades dos colaboradores da empresa pesquisada; 2) As estratégias de remuneração aumentam a motivação da equipe de trabalho da empresa pesquisada; 3) A Remuneração Estratégica atende os objetivos dos gestores da empresa pesquisada.

O objetivo geral proposto nesta pesquisa foi verificar como é aplicada Remuneração Estratégica nos colaboradores da empresa de telecomunicações. Especificamente procurou-se: 1) Relatar os tipos de Remuneração Estratégica existentes; 2) Identificar quais são os tipos de remuneração estratégica adotada pela empresa pesquisada; 3) Verificar se as estratégias de remuneração aumentam a motivação da equipe de trabalho da empresa pesquisada; 4) Verificar se a Remuneração Estratégica atende as necessidades dos colaboradores e os objetivos dos gestores da organização pesquisada.

\section{REFERÊNCIAL TEÓRICO}

O objetivo desta seção é estabelecer os conceitos fundamentais para a pesquisa. São abordados os conceitos de Remuneração Estratégica e os seus variados tipos existentes no mercado, o Planejamento Estratégico, Planejamento de Recursos Humanos, Responsabilidade Social Interna.

\subsection{Remuneração Estratégica}

A Remuneração Estratégica é um novo conceito de gestão empresarial que visa a eficiência e eficácia de remunerar os seus colaboradores buscando resultados positivos. De acordo com Rodrigues (2006) o fator estratégico de uma organização está voltado ao reconhecimento do trabalho dos funcionários, e este fator deve ser por programas de remuneração variável que visa beneficiar e flexibilizar a recompensa dos colaboradores. Nas últimas décadas cresce o entendimento do funcionário como um colaborador da empresa, o qual passa a ser observado não como um empregado que cumpre o seu trabalho, mas sim com uma visão estratégica de um colaborador da empresa que faz seus serviços diariamente para 
que a empresa se destaque, e isso se dá ao alto nível da visão do empreendedor atual.

Na opinião de Jorge (2007) a organização deve estar preparada para as mudanças radicais e imprevisíveis com a evolução tecnológica e os novos processos organizacionais, e para isso as empresas devem estabelecer estratégias de desenvolvimento e capacitação de seu pessoal. A Remuneração Estratégica é uma ligação entre o indivíduo e a nova realidade das organizações, novos padrões de remuneração estão sendo colocados em prática em algumas empresas, para que haja justiça na determinação da remuneração de cada profissional. Atualmente os maiores desentendimentos entre empregados e empregadores está na ausência de um programa realmente objetivo de mensuração que possa determinar o quanto vale o trabalho do colaborador, evidenciando que na atualidade os funcionários querem sua recompensa pelo seu trabalho e não pelo seu cargo.

Segundo Silva (2005) a Remuneração Moderna é um conjunto de recompensas que visam beneficiar os colaboradores da organização, e derruba o mito do sistema universal de gestão de salários e passa a ser considerada parte do sistema gerencial da empresa e se bem implantado pode ter um diferencial positivo. A remuneração tornou-se durante os anos uma das principais funções da empresa, merecendo uma atenção especial dos administradores e dirigentes. As organizações precisam desenvolver estratégias claras de Recursos Humanos para que possam incentivar o seu talento. $\mathrm{O}$ crescimento da importância de mensurar o Capital Humano é um moderno e sofisticado item para que os colaboradores fiquem atentos e busquem conhecimentos através de cursos preparatórios, treinamentos, entre outros.

\subsubsection{Sistema de Remuneração Estratégica}

No entendimento de Wood Jr. (2004, p. 39) "O sistema de Remuneração Estratégica é uma combinação equilibrada de diferentes formas de remuneração." O sistema de Remuneração Estratégica está ligado ao setor de recursos humanos da organização, e este deve levar em consideração que toda empresa precisa aplicar tipos de Remuneração Estratégica não somente em valores, mas também a título de reconhecimento, para empresa obter um bom desempenho tanto operacional como econômico. O sistema parte de uma idéia de variados tipos de remuneração adequados para cada organização, que analisa o trabalho do indivíduo e recompensa cada um pelo seu conhecimento, habilidades, capacidade, desempenho, entre outros, levando sempre em consideração que os colaboradores da empresa podem elevar a imagem e o crescimento da organização sempre que motivados para isto. Coopers e lybrand (1996) citam como é composto o sistema de Remuneração Estratégica, 
conforme mostra a Figura 01:

Figura 01: O conceito de Remuneração Estratégica.

Formas especiais de recompensa

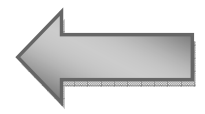

Remuneração por desempenho

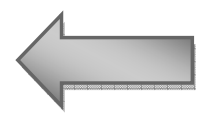

Base da

Fixa

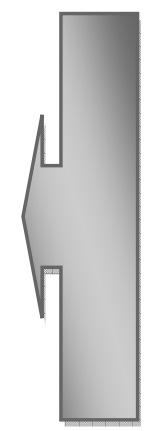

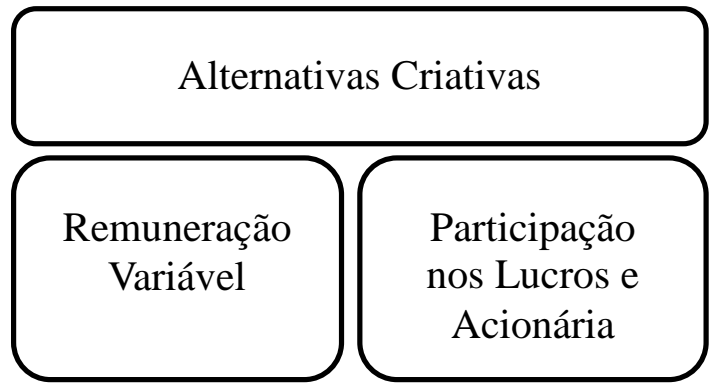

Salário Indireto

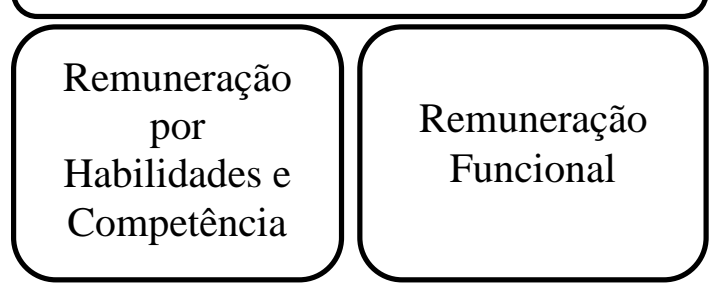

Fonte: Adaptado de Coopers \& Lybrand, 1996.

Esses são os componentes de um sistema de remuneração que explicam de que forma estão classificados os tipos de recompensa e as formas de remuneração a serem utilizadas por uma organização. A Remuneração por Habilidades e Competência, Remuneração Funcional compõe a base da remuneração, juntamente com o Salário Indireto eles formam a Remuneração Fixa do colaborador. As formas de remuneração por desempenho é composta pela Remuneração Variável e Participações nos lucros ou acionária, o sistema também possui outros tipos de recompensas no mercado específicas de algumas organizações que pode ser vista como Alternativas Criativas.

Face exposto, a seguir serão caracterizados os tipos de remuneração de remuneração existentes nas empresas, são elas: Remuneração Funcional, Remuneração por Competência e Habilidades, Salário Indireto, Remuneração Variável, Participação Acionária, os quais serão apresentados na seqüência:

\subsubsection{Remuneração Funcional}

Esse tipo de Remuneração pode ser chamado também como Plano de Cargos e 
Salários e tem o foco voltado para o cargo do colaborador dentro da organização que compreende uma forma tradicional de remunerar. A remuneração funcional da à sensação de igualdade entre os funcionários, pois esse tipo de remuneração parte de regras aplicáveis a todos na empresa, e acabam os colaboradores dos setores tendo um sentimento de justiça. Essa remuneração não deve ser extinta ou substituída por outros métodos de remuneração, ela tem que ser usada nas empresas, porém, com outras formas estratégicas de remuneração para que venham contemplar a necessidade e os objetivos da empresa e dos profissionais inseridos no ambiente.

\begin{abstract}
Remuneração Funcional ou tradicional, é determinada pela função (cargo) e ajustada ao mercado. Esse tipo de remuneração é o mais tradicional que existe. É também conhecido pela sigla PCS (Plano de Cargos e Salários). Mantém-se ainda como o modelo mais popular em uso. Grandes empresas que o utilizam tendem ao conservadorismo e à inércia. (WOOD JR., 2004, p.38)
\end{abstract}

Esse modelo de remuneração permite a clara visão da estrutura de cargos da organização, as responsabilidades, a competência, os salários. De acordo com Resende (2004) o plano de Cargos e Salários é um dos principais benefícios da remuneração funcional, para os gestores da empresa a remuneração funcional define a autoridade e responsabilidade nas questões salariais dos profissionais, avaliação do desempenho do funcionário na sua atividade dentro da organização, melhora no ambiente de trabalho através de pontos pré-definidos para subordinação dos empregados e autoridade dos encarregados, além de ter o controle de custo com a folha de pagamento e planejamento do mesmo. Segundo Resende (2004) este é o modelo tradicional de cargos e salários na forma de remuneração tradicional:

\title{
Quadro 01: Modelo de Cargos e Salários.
}

\begin{tabular}{|l|l|}
\hline Forte foco no cargo & Não integra planejamentos de RH \\
Forte foco no mercado & Sem avaliação de desempenho \\
Fracamente focado nas pessoas & Favorece reclamações na organização \\
$\begin{array}{l}\text { Fracamente focado em carreiras } \\
\text { Muito preocupado com tecnicismo e pouco } \\
\text { com a empatia }\end{array}$ & Dificulta relações trabalhistas \\
\hline
\end{tabular}

Fonte: Resende, 2004.

No quadro 01 pode-se visualizar que a Remuneração Funcional tem suas vantagens e desvantagens, por ela ser uma remuneração que tem o seu foco nos cargos da empresa, ela deve ser utilizada com outras alternativas de salário, pois atualmente é uma tendência das empresas analisar o desempenho de cada indivíduo. 


\subsubsection{Remuneração por Competência e Habilidades}

A Remuneração por Habilidades e Competência estabelece uma mudança na maneira de pensar e remunerar os profissionais. Esta remuneração é determinada pela formação e capacitação dos profissionais da empresa para responder ao ambiente mais complexo dos negócios. Segundo Jorge (2007, p. 111) “A necessidade deste tipo de remuneração surge em empresas que estão desenvolvendo projetos de reestruturação organizacional, nas quais se objetivam a redução de níveis hierárquicos”. Essa remuneração é uma nova idéia que vem sendo difundida no Brasil em meados da década de 90 e surgiu para inovar e mudar a remuneração tradicional. Ela analisa a competência e as habilidades do indivíduo e deixa de ser ligado ao cargo exercido. O forte crescimento das empresas segue ao lado da demanda por profissionais cada vez mais qualificados.

\footnotetext{
Esse tipo de remuneração tem seu papel fundamental na gestão de pessoas, constituindo uma grande evolução do modelo tradicional de cargos e salários. Busca, ainda, corrigir algumas deficiências de pressupostos e ultrapassadas, passando a alinhar os objetivos da organização com os aspectos inovadores de gestão de pessoas. (LOPES, 2010)
}

$\mathrm{Na}$ Remuneração por Habilidades a empresa foca em pagar a recompensa do funcionário pelo o que ele saber fazer e não pelo cargo. De acordo com Chiavenato (2005) existem dois modos de remunerar o colaborador por sua Habilidade: pelo conhecimento e multi-habilidades. A análise do conhecimento do funcionário segue uma idéia de adquirir formação, cursos, treinamentos que vão ajudar a difundir o conhecimento do cargo exercido na empresa. As multi-habilidades decorrem de mudança de comportamento por parte dos grupos de trabalho. Esse tipo de pensamento ajuda a mensurar a qualidade e evolução do trabalho realizado. Nesse tipo de remuneração o colaborador necessita de um número maior treinamento, pois ele desempenhará várias tarefas durante o seu serviço.

Já a Remuneração por Competência é definida como a qualidade do colaborador de resolver certos assuntos, capacidade de tratar de um determinado problema dentro do ambiente de trabalho. Para Wood Jr. (2004) a Remuneração por Competência supera algumas restrições da Remuneração por Habilidades, sendo que o aspecto principal é adotar esse sistema de uma forma criativa que venha contribuir para estratégia da empresa, pois este sistema de remuneração analisa a criatividade e a personalidade do colaborador, sendo utilizada primeiramente para o corpo executivo ou gerencial da empresa e em seguida para 
todos os trabalhadores.

\subsubsection{Salário Indireto}

De acordo com Chiavenato (2005 p. 292) os salários indiretos são "Os benefícios e serviços aos empregados que visam satisfazer vários objetivos econômicos, sociais e individuais". Para Wood Jr. (2004 p. 38) o salário indireto existe de duas formas "Na forma mais tradicional, os benefícios variam de acordo com o nível hierárquico. $\mathrm{Na}$ forma flexibilizada, cada colaborador escolhe o pacote de benefícios de acordo com suas necessidades [...]”. São formas da empresa se tornar socialmente responsável com seus colaboradores, como por exemplo: plano de saúde, vale alimentação, seguro de vida, complemento de aposentadoria. Além disso, é uma forma de fazer permanecer os funcionários dentro da organização e atrair profissionais de alto nível.

[...] O beneficio deve funcionar como instrumento de atração e de retenção de pessoal e visam: Reduzir a fadiga psicológica e física das pessoas. Apoiar o recrutamento de pessoal e atrair candidatos. Reduzir a rotatividade de pessoal e fixar o pessoal da empresa. Minimizar o custo das horas trabalhadas Proporcionar melhor qualidade de vida às pessoas. (CHIAVENATO, 2005, p. 292)

De acordo com Minamade (2004) cada empresa deve procurar analisar o perfil de seus colaboradores, os planos que melhor encaixa com seus profissionais devem ser escolhidos pela empresa analisando os custos de cada um. A flexibilização dos benefícios é a melhor alternativa de aproximar a empresa do empregado, dando a opção para ele escolher entre benefícios que são mais próximos de sua realidade familiar e estilo de vida, esses planos flexíveis possibilitam que a empresa possa ajustar o valor investido e o valor pago aos funcionários, dessa forma, podendo equilibrar os custos.

\subsubsection{Remuneração Variável}

O pagamento de participação nos lucros, gratificação e prêmios é a forma mais nítida de Remuneração Variável. De acordo com Chiavenato (2005, p. 299) “A Remuneração Flexível ou Variável é uma maneira de adequar o pacote às necessidades individuais de cada pessoa". Já para Jorge (2007, p. 138) "A remuneração total é composta, da remuneração fixa, da remuneração indireta, e da remuneração variável. Dessa forma, remuneração variável é a parte da remuneração total atrelada à obtenção de resultados". Este tipo de sistema é o conjunto de recompensas que complementam o salário fixo do funcionário, e tem como 
objetivo a motivação do individuo, compartilhar os momentos e bons e ruins da empresa e partir da mudança de custo fixo em custo variável.

\begin{abstract}
Os planos de tipo menu oferecem à pessoa um pacote total de remuneração direta e indireta em que ela deve escolher como alocar ou gastar o seu dinheiro. Pode receber tudo em dinheiro ou parte em benefícios sociais. Em alguns planos, a escolha ocorre somente dentro da categoria de benefícios. Esse tipo de sistema é desenhado para assegurar que a pessoa esteja trabalhando para receber recompensas que ela realmente quer receber. (CHIAVENATO, 2005, p. 299)
\end{abstract}

No entendimento de Silva (2005) o complemento do salário através da Remuneração Variável está atrelado ao seu desempenho operacional, que pode vir a variar durante o tempo. A Remuneração Variável deve ser ligada ao objetivo do negócio e deve contemplar tanto o funcionário como a empresa, este tipo de remuneração pode estar ligado ao lucro ou também pode estar atrelada às previsões de receita que a organização estima, sendo importante que os dirigentes fiquem atentos à legislação trabalhista vigente, pois, o funcionário, por exemplo, não pode ficar somente com a remuneração variável, ele deve ter um teto salarial. Essa remuneração tem algumas vantagens, como: aumento no desempenho operacional, aumento da motivação dos profissionais envolvido, a Remuneração Variável fica atrelada ao sucesso do negócio.

\title{
2.1.1.5 Participação Acionária
}

Conforme Wood Jr. (2004) a Participação Acionária é considerada uma remuneração de longo prazo, pois esta oferece para o colaborador uma co-participação da empresa, entendendo assim uma relação de compromisso do funcionário com a organização. Sendo difundida atualmente no Brasil, essa estratégia é uma forma sofisticada de remunerar os funcionários, atendendo assim a evolução que existe no ambiente organizacional, fazendo que seus colaboradores principalmente os executivos que são mais recompensados por esse tipo de remuneração, façam esforços para manter as ações da empresa valorizada no mercado de capitais. No Brasil a aplicação dessa estratégia é complicada porque as empresas não estão acostumadas a usar esse tipo de remuneração e quando utilizam é somente para diretores ou gerentes, não abrangendo para ou outros colaboradores da empresa.

\subsection{Planejamento Estratégico}


Segundo Mintzberg (2004) Planejamento Estratégico é um procedimento que os empresários utilizam para produzir um resultado articulado pelos próprios gestores, na forma de um sistema integrado de decisões. O objetivo é gerar lucro, sendo planejamento ligado ao crescimento da organização e também sujeito a incertezas a respeito dos eventos ambientais, assim, esse procedimento tem suas decisões baseado em suposições e não em dados que seja concretos, ele é feito para o futuro da organização com orientação sempre em longo prazo. Existem vários modelos de Planejamento Estratégico com possibilidade de implantação nas empresas, porém deve-se levar em consideração para a escolha o tipo de empresa e o ambiente externo que ela está inserida para se aplicar o plano.

De acordo com Cavalcanti (2001) a estratégia ao ser elaborada deve seguir algumas premissas, como: Definição da missão, porque a organização existe no mercado e qual sua contribuição para o ambiente; as metas devem ter delimitação temporal e podem ser ajustadas; os objetivos deverão estar de comum acordo com a missão da empresa até mesmo para viabilizar o monitoramento; as estratégias deverão explicar como serão atingido os objetivos; planejar, realizar e controlar as ações.

Para Ansoff (1993) os maiores obstáculos enfrentados por uma organização na elaboração de um planejamento estratégico são a direção que poderá prosseguir para alcançar um crescimento visando o futuro e como conscientizar a sua equipe de profissionais nesse mesmo objetivo. Apesar deste obstáculo, Certo e Peter (1993) comentam que o maior benefício da gestão estratégica é o de permitir que as diversas funções organizacionais e seus vários níveis hierárquicos trabalhem na mesma direção, ou seja, contribuam para a implementação da estratégia da empresa.

\subsubsection{Planejamento de Recursos Humanos}

As empresas atualmente adotam planejamento estratégico para o setor de vendas, produção, finanças, atendimento ao consumidor, entre outros, para obter resultados satisfatórios em seu crescimento econômico e desenvolvimento operacional. De acordo com Lucena (1999) O Planejamento de Recursos Humanos surge como um novo conceito planejamento estratégico, para alinhar objetivos da organização com gerenciamento de pessoal e alinhar a filosofia de trabalho da empresa com os modos de exercer cada função. A preocupação com o futuro da empresa é cada vez mais evidente entre o ambiente empresarial, e com isso o Planejamento de Recursos Humanos se torna imprescindível para o bom relacionamento com as pessoas da empresa e até mesmo fora dela. Esse tipo de planejamento 
vai além do pensamento de contemplar somente os funcionários, ele parte de um propósito de analisar todas as pessoas da empresa incluindo diretores, proprietários, clientes e até mesmo pessoas que estão ligados na empresa indiretamente.

[...] as revisões e reestruturação em qualquer segmento organizacional já são práticas comuns nas organizações tendo em vista a realidade mutativa do contexto empresarial. Da mesma forma, a Área de Recursos Humanos por fazer parte deste contexto precisa também rever suas necessidades de adaptação a fim de ajustar-se ao processo de transformação organizacional. (LUCENA, 1999, p.60)

Adotar a Remuneração Estratégica dentro do Planejamento de Recursos Humanos é essencial e na maioria das empresas o salário se torna o objetivo principal do plano. Segundo Franco (2007) a estrutura e descrições de cargos é um processo que visa estabelecer as responsabilidades de cada função e a distribuição de tarefas por campo de atuação, facilitando a estrutura do salário dos colaboradores. O sistema de remuneração é feito em uma etapa do Planejamento de Recursos Humanos para a obtenção de custo-beneficio em um processo análise de funções e das pessoas inseridas na organização, pois um bom método de Remuneração Estratégica é aquele que se autofinancia.

\subsection{Valorização da Responsabilidade Social Interna}

A competitividade da empresa vem através da Inteligência Organizacional e com isso a Responsabilidade Social é um dos itens importantes e essencial para nova era de gestão empresarial. A Responsabilidade Social de uma empresa parte de uma idéia de preocupação que surge com o meio ambiente, a comunidade, os consumidores, os colaboradores e com isso a necessidade de implantar métodos estratégicos. A preocupação com a parte social vem crescendo em diversas instituições, que se formalizam e adotam uma nova postura socialmente responsável para atuar no universo organizacional com um diferencial competitivo.

Responsabilidade Social pode também ser o compromisso que a empresa tem com o desenvolvimento, bem-estar e melhoramento da qualidade de vida dos empregados, suas famílias, sua comunidade em geral. Assim, a responsabilidade social não se refere à sociedade como um todo, mas especifica os funcionários, as famílias e a comunidade. (REIS, 2009, p. 11).

De acordo com Melo Neto (1999, p.78) "A responsabilidade Social de uma empresa consiste na sua decisão de participar mais diretamente das ações comunitárias na região em que está presente e minorar possíveis danos ambientais do tipo de atividade que exerce". 
Além da Responsabilidade Social Externa que corresponde à preocupação com o meio ambiente, comunidade e ações sociais, uns dos focos que a Organização deve explorar é a Responsabilidade Social Interna, que traz como beneficiário os seus colaboradores e dependentes, de acordo com Kroetz (2000, p.81) "Disseminar conceitos de responsabilidade social e ambiental, fabricar produtos e oferecer serviços com qualidade são condições fundamentais para permanecer na área da economia do conhecimento [...]”. O investimento no sistema de Remuneração Estratégica traz para os funcionários a motivação de trabalhar em conjunto com a empresa, dessa forma possibilitando capacitação e desenvolvimento profissional compreendendo uma forma de gestão da Responsabilidade Social Interna que visa diretamente a qualidade de seu pessoal para obter bom resultado operacional.

\footnotetext{
Contudo, apoiar o desenvolvimento da comunidade e preservar o meio ambiente não são suficientes para atribuir a uma empresa a condição de socialmente responsável. É necessário investir no bem-estar dos seus funcionários e dependentes e num ambiente de trabalho saudável, além de promover comunicações transparentes, dar retorno aos acionistas, assegurar sinergia com seus parceiros e garantir a satisfação dos seus clientes ou consumidores. (MELO NETO, 1999, p.78)
}

A Responsabilidade Social de acordo com Rodrigues (2005) é uma obrigação ética das empresas mesmo que não previsto na lei, pois, a sociedade tem a necessidade de que as empresas adotem medidas para diminuir as conseqüências nelas causadas, dessa forma não levando somente em consideração para tomada de decisão aspectos econômicos. A importância de adotar o conceito de Responsabilidade Social, a preocupação de implantar métodos de ser socialmente responsável dentro da organização tem uma relevância muito grande, partindo do princípio que uma empresa não pode querer somente ser responsável externamente sendo que dentro da organização ela não tem essa responsabilidade, pois, os funcionários também fazem parte da comunidade e quando se fala em Responsabilidade Social as empresas devem seguir um modelo de contemplar a comunidade como um todo.

\section{METODOLOGIA}

Esse trabalho foi realizado em uma empresa localizada na cidade de Tangará da Serra/MT do setor de telecomunicações. A abordagem do projeto foi qualitativa e quanto aos objetivos foi descritiva e explicativa. Utilizou-se como metodologia o estudo de caso de caráter exploratório, dados bibliográficos coletados de livros, pesquisa eletrônica e artigos específicos. Foram utilizadas técnicas de coleta de dados primários e secundários. A coleta de 
dados primários foi realizada através de dados levantados por questionários com perguntas abertas e fechadas (simples e de múltipla escolha, e espaço reservados para comentários) sendo informado ao entrevistado o objetivo da pesquisa. A coleta de dados secundários foi realizada através da análise de documentos existentes no setor de recursos humanos da organização, como: folha de pagamento dos colaboradores, e-mails eletrônicos dos diretores da empresa.

A empresa, objeto dessa pesquisa, conta com nove colaboradores no seu ambiente operacional e dois gestores sendo um subgerente e o outro gerente geral. O primeiro questionário foi aplicado para todos os profissionais da área operacional buscando saber qual o nível de satisfação com a remuneração e se as necessidades básicas estão sendo suprido pela mesma. O segundo foi aplicado aos gestores para verificar seu entendimento quanto aos objetivos da remuneração aplicada e se estes estão sendo alcançados. A pesquisa realizou-se entre os dias 24/03/11 a 25/03/11 no horário de trabalho dos gerentes e funcionários no momento em que eles não estavam em atendimento.

\section{RESULTADOS E DISCUSSÕES}

Nesse momento serão apresentados os resultados obtidos através da pesquisa realizada na empresa de telecomunicações com o objetivo geral, o presente, propõe verificar como é aplicado a Remuneração Estratégica na empresa pesquisada. É apresentado o objeto de estudo, os tipos de remunerações utilizados bem como a descrição da remuneração de cada atividade, além disso, será discutida a percepção dos colaboradores e gestores da empresa em relação às estratégias de remuneração evidenciando os pontos mais relevantes.

\subsection{A Empresa Objeto do Estudo de Caso}

Em maio de 1995, o governo deu inicio a uma ampla reforma do sistema regulatório das telecomunicações brasileira, logo em 1997 com a "Lei Geral das Telecomunicações" que sustentou o desenvolvimento de uma nova estrutura normativa foi criada em 1998 mais 12 novas companhias holdings onde a empresa objeto desse estudo era uma delas, em 2005 com nova reestrutura societária a companhia tem um novo nome empresarial e conta com 13 anos de existência. Estabelecida no mercado e classificada entre: "150 melhores empresas para se trabalhar no Brasil” no guia da Exame/Você S.A.;"100 melhores empresas para se trabalhar GPTW 2010" e as "70 melhores empresas de TI e Telecom para trabalhar" do Great Place to 
Work a companhia vende celulares e seus serviços de telecomunicações móveis, transmissão de dados e internet em todo território nacional, é a maior empresa do setor no país e o maior grupo de telefonia celular no hemisfério sul. Em 2009 eram 10.598 em 2010 a companhia encerra o ano com um total de 13.419 colaboradores, concentrando o maior número de colaboradores nas áreas de Marketing, Técnica e Operações.

Quadro 02: Quantidade total de colaboradores no Brasil da empresa pesquisada em Março de 2011.

\begin{tabular}{|l|c|c|c|}
\hline Área de Atividade & $\mathbf{2 0 0 9}$ & $\mathbf{2 0 1 0}$ & \% var \\
\hline Técnica e Operações & 2.333 & 2.294 & $-1,7 \%$ \\
\hline Marketing e Vendas & 5.214 & 8.288 & $59,0 \%$ \\
\hline Atendimento a Clientes & 1.303 & 1.187 & $-8,9 \%$ \\
\hline Suporte Financeiro e Administrativo & 1.748 & 1.650 & $-5,6 \%$ \\
\hline Total & $\mathbf{1 0 . 5 9 8}$ & $\mathbf{1 3 . 4 1 9}$ & $\mathbf{2 6 , 6 \%}$ \\
\hline
\end{tabular}

Fonte: Elaborado pelos autores.

A empresa conta com um de seus estabelecimentos na cidade de Tangará da Serra/MT desde ano 2007, tendo como principal atividade a venda de celulares e planos para linha móvel e internet, nesta cidade a empresa conta com onze colaboradores distribuídos diferentes atividades. A estrutura organizacional da empresa é apresentada na figura 02:

Figura 02: Organograma da empresa pesquisada em Março de 2011. 


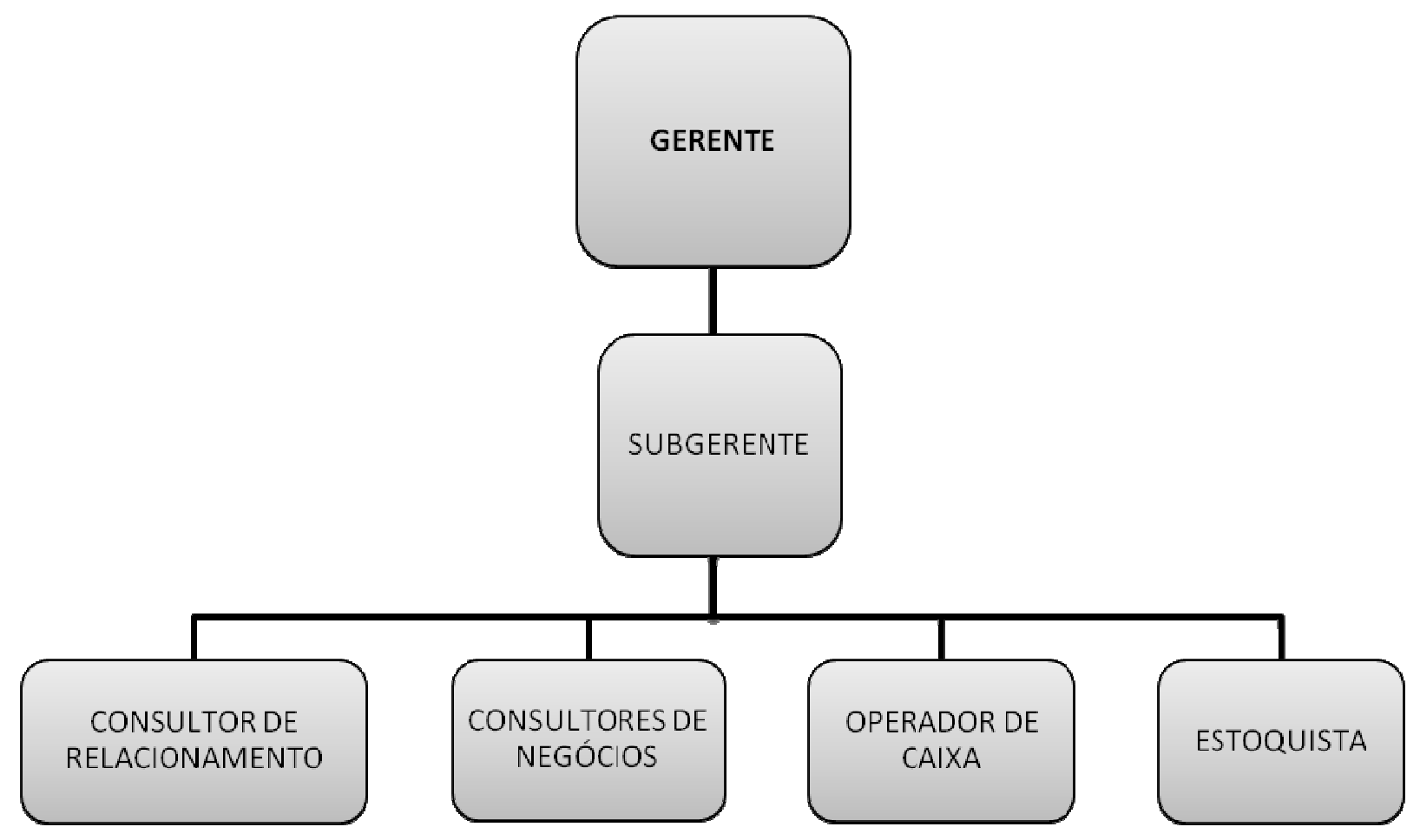

Fonte: Elaborado pelos autores.

Abaixo estão relacionados às funções dos cargos descritos no organograma:

- Gerente: Responsável por todo planejamento e controle da execução de trabalhos da empresa.

- Subgerente: Subordinado ao Gerente, essa pessoa é responsável por ajudar na gerência da empresa.

- Consultor de Relacionamento: Esse Consultor é o profissional qualificado para resolver e encaminhar todas as solicitações dos clientes, propondo a melhor solução com rapidez e qualidade.

- Consultores de Negócios: Responsável por identificar as melhores alternativas para o cliente em caso de vendas de aparelhos e planos de linha móvel e internet.

- Operadora de Caixa: Responsável por registrar as vendas, pela parte financeira, e vendas de recargas de celulares pré-pagos.

- Estoquista: Tem a responsabilidade da organização do estoque da empresa e trocas de aparelhos.

\subsection{Descrição do atual Sistema de Remuneração da Empresa}

O sistema de remuneração praticado atualmente na empresa foi definido pelos diretores de toda a companhia. A equipe de trabalho da empresa tem o seu salário fixado acima da média de mercado e são remunerados através de salário indireto e remuneração 
variável. Os benefícios como: plano de saúde, vale alimentação e transporte são oferecidos para todos os colaboradores da organização, o colaborador que opta pelo vale alimentação é descontado um valor simbólico no seu recibo de pagamento mensal.

Já o Consultor de Relacionamento por ser um profissional que tem o primeiro contato com o cliente e controla o sistema eletrônico de senhas de atendimento na empresa ele é o funcionário que ganha o melhor salário da equipe do operacional, esse profissional juntamente com o Operador de Caixa além do seu salário base, são remunerados através do seu tempo de atendimento que é estipulado em torno de 10 minutos por cliente, sendo ainda também remunerados por alcance de metas de vendas coletivas. Esses itens, que são os fatores para a remuneração por metas, devem ser cumpridos acima de $80 \%$ percentual estabelecido pela companhia para que os colaboradores citados ganhem sua remuneração variável.

Os Consultores de Negócios são os profissionais que independentemente dos outros funcionários são recompensados por alcance de metas de vendas individuais, além deu seu salário base, essas pessoas ganham sua remuneração variável pelo alcance das metas que são estipuladas mensalmente pelos diretores da companhia, eles também são avaliados pelo seu atendimento através do Índice de Satisfação do Cliente (ISC), que é dado uma nota pelo cliente de 0 a 10 do seu nível de satisfação do atendimento, para isso a empresa estabelece que a média considerável seja 9,1. Esses funcionários são avaliados por esses dois itens de recompensa para que os mesmos ganhem sua remuneração variável.

Já o cargo de Estoquista tem seu salário base e participa somente dos benefícios que a empresa propõe para a equipe de trabalho, não sendo remunerado por alcance de metas. Os Gestores da empresa (gerente e subgerente) têm seu salário fixado e também são remunerados através do desempenho de todos colaboradores da empresa. Se todas as metas estipuladas pela companhia forem atingidas pela equipe de trabalho, os gestores são recompensados pelos seus esforços e ganham um percentual a mais na sua remuneração. Os Gestores são responsáveis pelo alcance dos objetivos da empresa, sendo os profissionais capacitados para repassar todas as informações da companhia sobre planos, benefícios, metas, todo e qualquer tipo de informações que irá influenciar no desempenho da organização.

A companhia ainda conta com a Participação nos Lucros ou Resultados (PLR), que é um tipo de remuneração variável e é uma ferramenta muito utilizada por várias organizações para auxiliar no cumprimento das estratégias da empresa. Essa recompensa é um plano que tem como objetivo de participações nos lucros da empresa que envolve todos os profissionais da organização. 


\subsection{A Percepção dos Colaboradores sobre a Remuneração}

Primeiramente foi levantando dados do grau de instrução da equipe de trabalho. Assim constatou-se que $11,1 \%$ possuem o ensino médio completo; $33,3 \%$ o ensino superior completo; 55,6\% o ensino superior incompleto. Revelando que a maioria de seus profissionais está cursando ou já concluiu o ensino superior, elevando assim, o grau de qualificação e desenvolvimento de sua equipe, conforme mostra o quadro 03:

Quadro 03: Percentual do grau de instrução dos entrevistados da empresa pesquisada em Março 2011.

\begin{tabular}{|c|c|c|c|}
\hline $\begin{array}{l}\text { Ensino Médio } \\
\text { Incompleto }\end{array}$ & $\begin{array}{l}\text { Ensino Médio } \\
\text { Completo }\end{array}$ & Superior Completo & Superior Incompleto \\
\hline $0 \%$ & $11,1 \%$ & $33,3 \%$ & $55,6 \%$ \\
\hline
\end{tabular}

Fonte: Elaborado pelos autores.

Quanto ao treinamento dos colaboradores, 22\% responderam que são mais ou menos treinados para execução de seus serviços, $78 \%$ disseram que são muito treinados e os outros itens não obtiveram percentual. Revelando que a organização investe em treinamento de pessoal, sendo um ponto positivo para o trabalho dos profissionais, como revela quadro 04 :

Quadro 04: Percentual do treinamento dos entrevistados da empresa pesquisada em Março 2011.

\begin{tabular}{|c|c|c|c|}
\hline Nenhum & Pouco & Mais ou Menos & Muito \\
\hline $0 \%$ & $0 \%$ & $22 \%$ & $78 \%$ \\
\hline
\end{tabular}

Fonte: Elaborado pelos autores.

Foi também questionado aos colaboradores se eles se sentem satisfeitos com seu salário atual, 44\% responderam que se sentem mais ou menos satisfeitos com a sua remuneração $56 \%$ responderam que se sentem muito satisfeitos, revelando que mais da metade dos funcionários da empresa estão de acordo com os tipos de remuneração utilizados, como mostra quadro 05.

Quadro 05: Percentual de satisfação do salário dos entrevistados da empresa pesquisa em Março 2011. 


\begin{tabular}{|c|c|c|c|}
\hline Nenhum & Pouco & Mais ou Menos & Muito \\
\hline $0 \%$ & $0 \%$ & $44 \%$ & $56 \%$ \\
\hline
\end{tabular}

Fonte: Elaborado pelos autores.

Em relação aos benefícios $100 \%$ dos entrevistados acham muito importante o Vale Alimentação e Plano de Saúde enquanto que para o Transporte 67\% dos colaboradores entendeu que é pouco importante e $33 \%$ vêem que é nada importante. O vale transporte não foi escolhido por nenhum profissional, se tornando nada ou pouco importante para toda a equipe. Assim, o beneficio que não é utilizado pelos colaboradores da organização deve ser revisto e analisado pela empresa, o quadro 06 demonstra a importância desses benefícios para os colaboradores:

Quadro 06: Percentual da importância dos benefícios para os colaboradores em Março 2011.

\begin{tabular}{|l|c|c|c|}
\hline Tipos de benefícios & Nada Importante & Pouco Importante & Muito Importante \\
\hline Vale Alimentação & $0 \%$ & $0 \%$ & $100 \%$ \\
\hline Plano de Saúde & $0 \%$ & $0 \%$ & $100 \%$ \\
\hline Transporte & $33 \%$ & $67 \%$ & $0 \%$ \\
\hline
\end{tabular}

Fonte: Elaborado pelos autores.

Ainda em relação aos benefícios, pode-se constatar que $22 \%$ dos colaboradores afirmam que os benefícios atendem mais ou menos necessidades básicas, $78 \%$ afirmam que sim, que suas necessidades básicas são supridas, o que revela que essa recompensa ofertada pela empresa está atingindo o objetivo que conforme Wood Jr. (2004) é atender as necessidades básicas e incentivar os funcionários, que logo tem impacto direto sobre a qualidade de vida, influindo sobre a sua segurança e sobre sua condição de vida, como demonstra a figura 03 :

Figura 03: Percentual de satisfação dos entrevistados da empresa pesquisada com os benefícios em relação as suas necessidades básicas em Março 2011. 


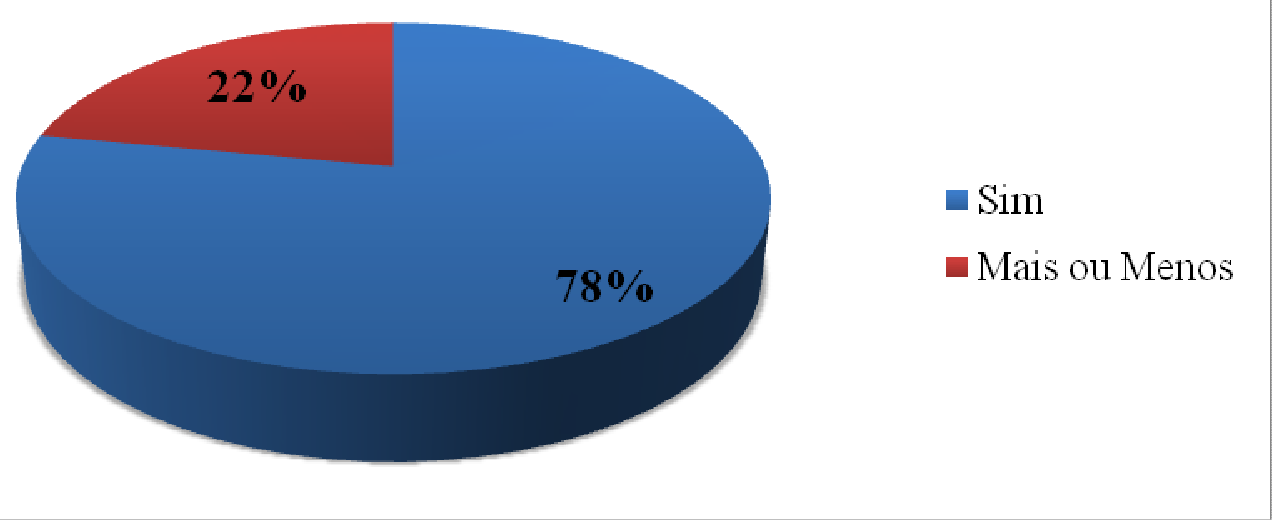

Fonte: Elaborado pelos autores.

Os benefícios são fatores decisivos em retenção de novos talentos e são utilizados para incentivar o profissional, além disso, para empresa reduz o custo de encargos sociais referente à folha de pagamento. Porém, quando questionados aos profissionais se eles preferiam receber todos esses benefícios em valores monetários sete pessoas das nove responderam que sim, e um ainda afirmou que: "Eu prefiro receber em dinheiro, porque prefiro gastar como eu achar melhor". Com isso percebesse que na empresa esse tipo de remuneração não é totalmente aceito, ou seja, os colaboradores não se sentem totalmente satisfeitos.

Segundo Araujo (2009) “[...] procura-se deixar claro que a motivação é algo da pessoa. Ninguém põe motivação na cabeça de ninguém. O que gestores de pessoas têm de fazer é satisfazer às mais variadas demandas individuais". É possível observar que o nível de motivação dos funcionários com relação à remuneração aplicada é mediano, pois $22 \%$ se sentem motivados para o trabalho com o sistema de remuneração e $78 \%$ se sentem mais ou menos motivados, conforme mostra a figura 04:

Figura 04: Percentual de motivação dos entrevistados com relação à remuneração aplicada da empresa pesquisada. Março 2011.

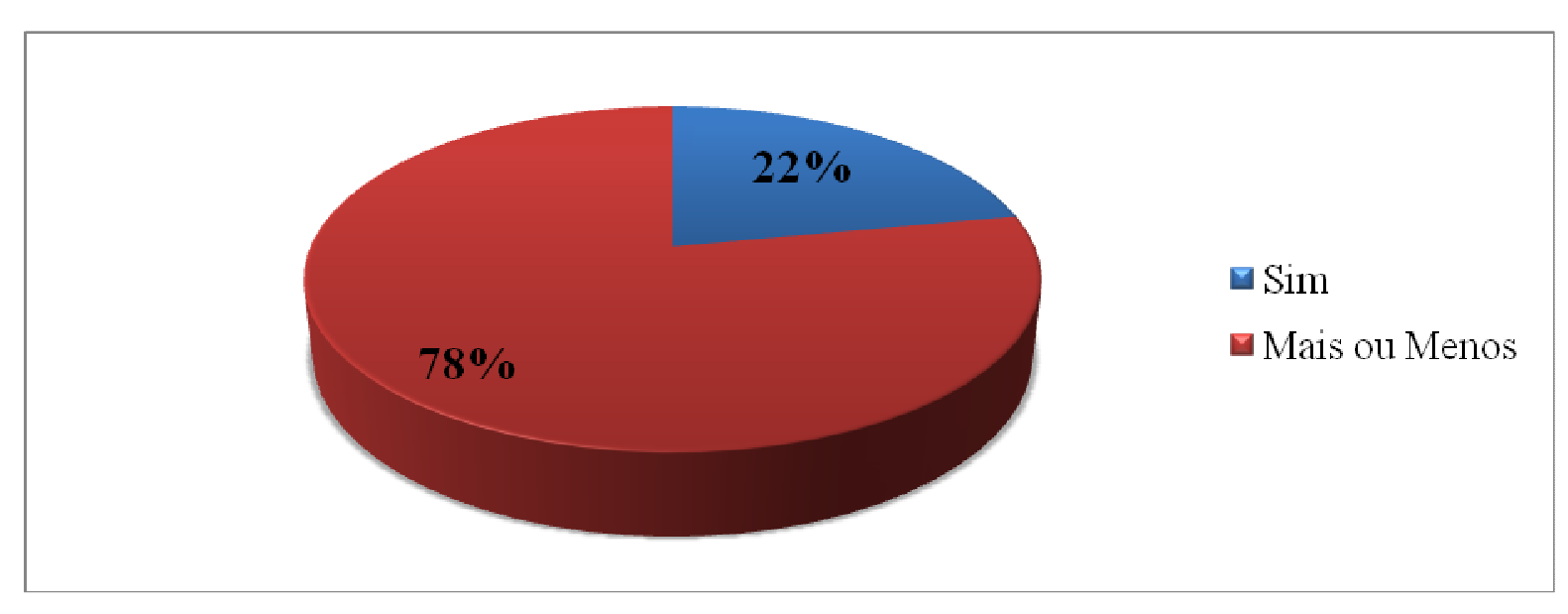


Fonte: Elaborado pelos autores.

Foi questionado aos colaboradores se eles concordam com a remuneração por alcance de metas de vendas, e obtiveram-se os seguintes percentuais de $33 \%$ responderam que estão de acordo e $66 \%$ disseram que concordam mais ou menos. As pessoas que disseram que concordam mais ou menos são todos dos cargos de Consultor de Negócio e Consultor de Relacionamento, sendo esses os profissionais mais exigidos e cobrados pelo gerente para atingir metas e conseqüentemente aumentar o faturamento do comércio. Todos comentaram nas respostas do questionário que se sentem muito pressionados pelo gerente em alcançar essas metas estabelecidas pelos diretores da organização, e ainda informalmente disseram que os profissionais que não alcançam as metas são normalmente demitidos.

De acordo com Poleti (2008) o fato que é pertinente alertar que a pressão excessiva pode se tornar um círculo prejudicial, podendo ser caracterizado como assédio moral, pois cada indivíduo tem níveis variados de capacidade para absorver informações e transformá-las em resultado. Ser pressionado além do limite leva profissionais bem treinados, artistas de sucesso e executivos preparados a abrir mão de reconhecimento, prestígio e dinheiro em busca daquilo que perderam no trabalho: qualidade de vida.

\subsection{A Percepção dos Gestores sobre a Remuneração}

Na opinião de Chiavenato (2005, p. 83), “a percepção envolve o conhecimento e a interpretação dos objetos, símbolos e pessoas de acordo com as experiências anteriores da pessoa". A empresa está preocupada em remunerar a sua equipe de forma que venha trazer benefícios para empresa e para os funcionários, os gestores da empresa têm interesse com desenvolvimento dos seus colaboradores para que a comércio consiga sempre atingir metas estabelecida.

Os gerentes da empresa foram interrogados quanto ao nível de importância o qual varia de 1 a 4, sendo o primeiro o mais importante e o quarto o menos importante, quanto aos objetivos da organização com a remuneração aplicada. Nesse sentido a resposta foi unanime entre os dois gestores, o objetivo principal da organização é incentivar seus colaboradores para alcançar metas estabelecidas pela empresa; o segundo objetivo é atrair novos talentos para a organização; o terceiro é motivar a equipe de trabalho para execução de tarefas e o quarto é atender as necessidades básicas dos colaboradores, como revela o quadro 07: 
Quadro 07: Objetivos da empresa pesquisada com a remuneração aplicada em Março 2011.

\section{REMUNERAÇÃO ESTRATÉGICA}

\section{$1^{\circ}$ Incentivar a venda a atingir metas estabelecidas pela empresa.}

$2^{\circ}$ Atrair novos talentos para a organização.

$3^{\circ}$ Motivar a equipe de trabalho para execução de tarefas.

$4^{\circ}$ Atender as necessidades básicas dos colaboradores.

Fonte: Elaborado pelos autores.

Nota-se que os gestores da organização dão muita ênfase ao primeiro objetivo da empresa que é o alcance de metas de vendas, e não dão muita importância ao objetivo que se refere às necessidades básicas de seus colaboradores. Na opinião de Maslow (1983) o primeiro ponto da necessidade humana que deve ser suprido é as necessidades fisiológicas, como mostra figura 05:

Figura 05: A pirâmide de Maslow.

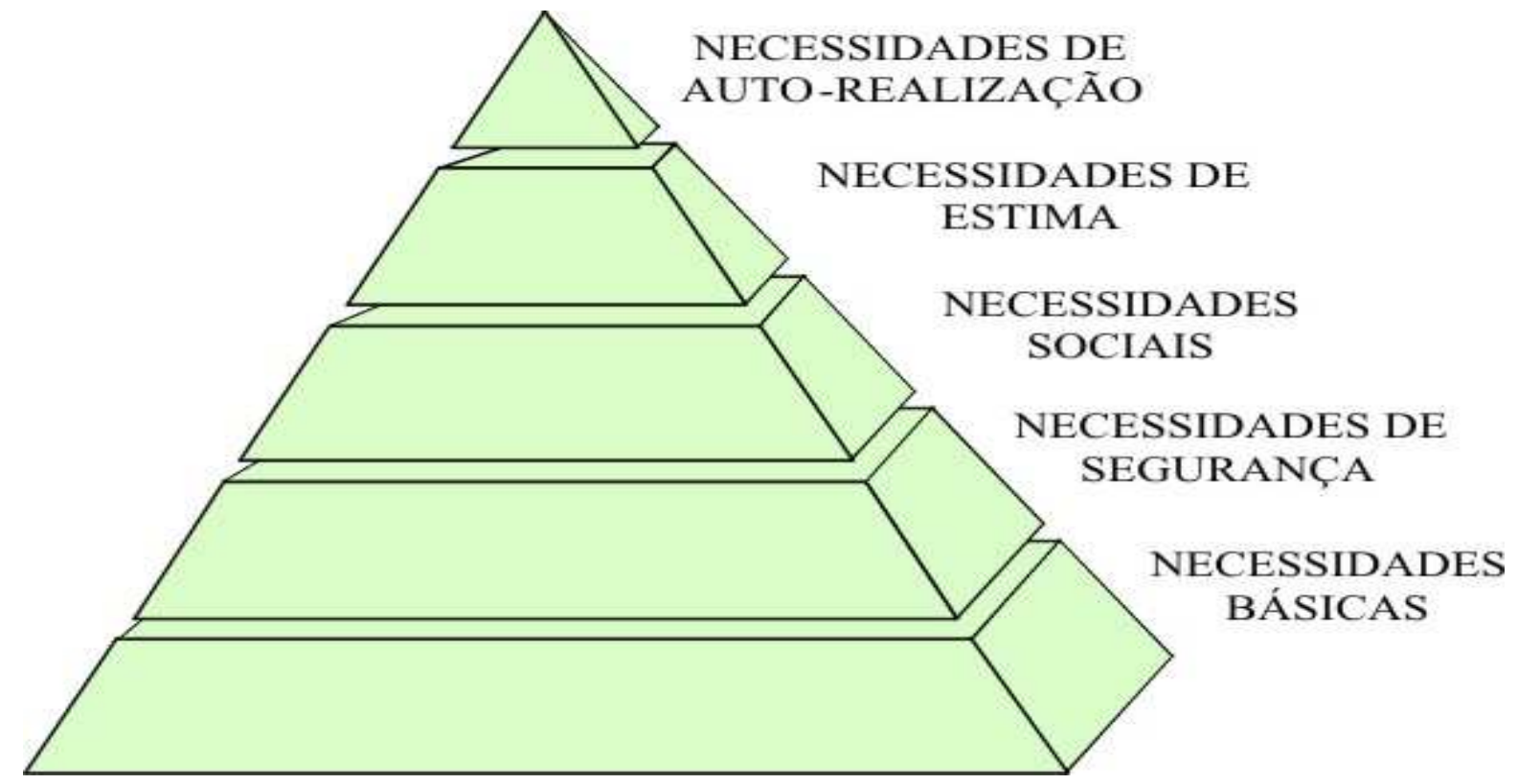

Fonte: Maslow (1983).

Dessa forma, os lideres da organização devem levar em consideração que o objetivo de atender as necessidades básicas dos profissionais precisa ser importante para empresa, pois é suprindo as necessidades humanas dos colaboradores que a organização poderá incentivar a venda, motivar e dar qualidade e vida ao funcionário. 
Ao serem perguntados se os objetivos da empresa com a Remuneração Estratégica utilizada estão sendo alcançados, o gerente geral disse que os objetivos são atingidos e ainda comentou que os tipos de remuneração que empresa oferece é ideal para organização; já o sub-gerente respondeu que os objetivos estão sendo alcançados pela organização, porém ele comentou que poderia ter algumas pequenas melhorias para o negócio ter menos rotatividade na área operacional.

$\mathrm{Na}$ opinião dos gestores a remuneração oferecida aos colaboradores interfere na tomada de decisão da organização, haja vista que a tomada de decisões em relação às vendas de celulares, planos pré-pagos e pós-pagos, promoções, e outros planejamentos da organização são desenvolvidos analisando também como a remuneração dos funcionários pode vir a trazer os resultados que a empresa espera nesses projetos e como o ambiente de trabalho pode se tornar mais agradável para os mesmos. Os gestores ainda, disseram que a remuneração dos funcionários é um fator estratégico da empresa e que as reuniões que participam com diretores de toda a companhia, o item salário é sempre discutido com uma forma melhoria da capacidade da organização de se estabelecer no mercado.

Conforme enfatiza Fischer (2002) neste cenário de mercado o comportamento humano e o capital intelectual passou a integrar o caráter intrínseco do negócio, tornando-se um fator de diferenciação e reforçando a vantagem competitiva. Em uma organização os profissionais procuram entre outras coisas uma melhoria de sua renda.

A visão que os colaboradores e gestores têm da empresa que trabalham é muito importante para a organização e para o desenvolvimento profissional de cada um. A percepção dos nove colaboradores envolvidos no operacional e dos dois gestores sobre a remuneração é diferenciada, porém eles reconhecem que poucas empresas trabalham com esses tipos de remuneração e se sentem privilegiados por fazerem parte da organização.

\section{CONSIDERAÇÕES FINAIS}

Para o desenvolvimento deste estudo foi abordado o seguinte problema: Como a Remuneração Estratégica é percebida pelos colaboradores e gestores do comércio de telecomunicações. Assim percebeu-se como necessário que a empresa análise se o sistema de remuneração que está sendo aplicado dentro da organização, para verificar se atende os critérios e objetivos dos gestores e se também atende as mais variadas necessidades individuais dos colaboradores.

Desse modo a responder o problema levantado foi consideradas três hipóteses: a 
primeira que se referia que a Remuneração Estratégica atende as necessidades dos colaboradores, foi confirmada, pois constatou-se que os benefícios oferecidos pela empresa atende as necessidades básicas dos profissionais.

Já a segunda que era relacionar o aumento da motivação através das estratégias de remuneração, foi refutada, pois identificou-se que os funcionários não se sentem motivados com a Remuneração Estratégica devido à pressão excessiva no caso da Remuneração Variável que diz respeito a alcance de metas de vendas.

A terceira hipótese que se referia que a Remuneração Estratégica atende os objetivos dos gestores, foi confirmada, pois constatou-se que as estratégias de remuneração atendem os objetivos propostos dos gerentes e pode-se constatar que a estratégias da empresa com a remuneração está interligado aos objetivos da organização

Em se tratando dos objetivos pode-se dizer que o objetivo geral foi alcançado, pois foi possível verificar aplicabilidade da Remuneração Estratégica na empresa pesquisada, verificou-se alguns aspectos principais como: tipos de Remuneração Estratégica, motivação da equipe de trabalho, percepção dos colaboradores e gestores sobre a recompensa. Em relação aos objetivos específicos: foram relatados os tipos de Remuneração Estratégica utilizada no mercado atualmente para obtenção de conhecimento sobre o assunto; foi possível identificar que as estratégias de remuneração aplicada nos colaboradores são a Remuneração Variável e o Salário Indireto; em relação à motivação da equipe de trabalho foi possível identificar através da entrevista aplicada que a Remuneração Estratégica utilizada não está aumentando a motivação dos profissionais; e ainda verificou-se a percepção dos colaboradores e gestores da empresa e pode-se constatar que a remuneração é percebida de formas diferentes entre empregado e empregador.

Por meio desse estudo na empresa foi possível visualizar que a Remuneração Estratégica está interligada com o objetivo da empresa, mas não está incentivando os funcionários ao trabalho. Através da pesquisa determinadas considerações foram abordadas devido aos resultados nela apresentados, sugere-se que:

- Primeiramente a empresa precisa tratar como fator importante de remuneração atender as necessidades dos colaboradores, pois como foi visto a empresa antes de tudo deve sanar as variadas necessidades básicas dos seus funcionários.

- A remuneração por alcance de metas deve ser utilizada para motivar e incentivar o colaborador a venda, mas não necessariamente precisa ser a principal Remuneração Estratégica, a empresa pode adotar outros tipos de recompensa como, por exemplo, a remuneração por habilidades e competência. 
- Não é interessante para empresa manter o benefício de vale transporte, pois todos os colaboradores não utilizam. É necessário oferecer outros benefícios, como: Plano de Previdência Privada, Combustível, Auxilio farmácia, Empréstimos, entre outros.

\section{BIBLIOGRAFIA}

ANSOFF, H. IGOR. Implantando a administração estratégica. São Paulo: Atlas, 1993.

ARAUJO, Luis César G. de. Gestão de pessoas: estratégias e integração organizacional. $2^{\circ}$ ed. São Paulo: Atlas, 2009.

CAVALCANTI, Marly. Gestão Estratégica de Negócios. São Paulo: Pioneira Thomson Learning, 2001.

CERTO, S.S. \& PETER J. P. Administração estratégica: Planejamento e implantação da estratégia. São Paulo. Makron Books, 1993.

CHIAVENATO, Idalberto. Gerenciando com as pessoas: transformando o executivo em um excelente gestor de pessoas. Rio de Janeiro - RJ: Editora Elsevier, 2005.

COOPERS \& LYBRAND. Remuneração Estratégica - A nova vantagem competitiva. São Paulo: Atlas, 1996.

FISCHER, A. L. Um resgate conceitual histórico dos modelos de gestão de pessoas. As pessoas na organização. São Paulo: Gente, 2002.

FRANCO, José de Oliveira. Cargos, Salários e Remuneração. Curitiba/PR: Iesde Brasil S.A., 2007.

JORGE, José Moacir. Remuneração Estratégica: como desenvolver atitudes empreendedoras por meio da remuneração. São Paulo - SP, editora LTR, 2007. 
KROETZ, C. E. S. Balanço Social. Teoria e Prática. São Paulo: Atlas, 2000.

LOPES, Manuel. Remuneração por Habilidades e Competência: um modismo ou uma ferramenta estratégica. Revista Liderança, 2010. Disponível em:

<http://www.lideraonline.com.br/php/materia.php?id=43084>. Acesso em: 19 set. 2010.

LUCENA, Maria Diva da Salete. Planejamento de Recursos Humanos. São Paulo - SP, Atlas, 1999.

MASLOW, A. H. Introdução à Psicologia do Ser. 2.ed. Rio de Janeiro: Eldorado, 1983.

MELO NETO, Francisco Paulo de. Responsabilidade Social e cidadania empresarial: a administração do terceiro setor. Rio de Janeiro - RJ: Editora Qualitymark, 1999.

MINAMADE, C. H. Sistemas de remuneração tradicionais e a remuneração estratégica. São Paulo: 2004. Disponível em:

<http://carreiras.empregos.com.br/carreira/comunique_se/col_leitor/120404-

sistemas_remuneracao_camila.shtm>. Acesso em: 21 out. 2010.

MINTZBERG, Henry. Ascensão e queda do planejamento estratégico. Porto Alegre: Bookman, 2004.

POLETI, Carlos Alberto. A Pressão no Trabalho: Desafio à Capacidade ou Assédio Moral. São Paulo: 2008. Disponível em:

http://www.umtoquedemotivacao.com/administracao/recursos-humanos/a-pressao-notrabalho-desafio-a-capacidade-ou-assedio-moral/. Acesso em: 07 de abr. 2011.

REIS, Carlos Nelson dos. Responsabilidade Social das Empresas e Balanço Social. 1 ed. São Paulo - SP, Atlas, 2009.

RESENDE, Enio. Entrevista com Enio Resende, disponível em www.rh.com.br - Acesso em 03/05/2011.

RODRIGUES, Júnia Marçal. Remuneração e Competências: retórica ou realidade? Belo Horizonte - MG, 2006. Disponível em: 〈http://www16.fgv.br/rae/artigos/4097.pdf>. Acesso em: 19 Set. 2010.

RODRIGUES, Maria Cecília Prates. Ação Social das Empresas Privadas: Como Avaliar Resultados? Rio de Janeiro - RJ, Editora FGV, 2005.

SILVA, Mateus de Oliveira. Sistemas Modernos de Remuneração. Rio de Janeiro - RJ, Qualitymark, 2005.

WOOD JUNIOR, Thomaz. Remuneração Estratégica. São Paulo - SP, Editora Atlas, $3^{\circ}$ edição, 2004. 